\title{
Prevalence and Risk of Polypharmacy among Community-Dwelling, Elderly Kuwaiti Patients
}

\author{
Nabil Ahmed Badawy ${ }^{a}$ Shokria Adely Labeeb ${ }^{b} \quad$ Mawaheb Falah Alsamdan ${ }^{a}$ \\ Badria Faleh Alazemi ${ }^{\text {b }}$ \\ aDepartment of Biomedical Science, College of Nursing, Public Authority for Applied Education and Training, \\ Al Shuwaikh, Kuwait; ${ }^{b}$ Department of Nursing, College of Nursing, Public Authority for Applied Education and \\ Training, Al Shuwaikh, Kuwait
}

\section{Highlights of the Study}

- This research is potentially the first work in Kuwait to estimate the prevalence of polypharmacy among elderly Kuwaiti patients.

- The current study revealed that a significant sector of the older Kuwaiti patient population has a high incidence of polypharmacy and thus is exposed to its potential hazards.

- This work highlights the need to revise the drug-dispensing policy among the older Kuwaiti population.

\section{Keywords}

Polypharmacy · Comorbidity · Elderly

\begin{abstract}
Objectives: To estimate the prevalence of polypharmacy in community-dwelling, older Kuwaiti patients, describe the number and types of drugs used, and identify risk factors associated with polypharmacy. Subjects and Methods: This was a descriptive cross-sectional questionnaire-based survey in which we interviewed 500 community-dwelling $\mathrm{Ku}$ waiti adults over 65 years of age. The data collection occurred during a 4-month period from March to July 2017. Results: Fifty-two percent $(n=260)$ of the patients were males, with a mean age of $71.73 \pm 5.32$ years. The prevalence of polypharmacy (5-8 drugs) and excessive polypharmacy (>8 drugs) was $58.4 \%(n=292)$ and $10.2 \%(n=51)$, respec-
\end{abstract}

tively. The risk factors associated with an increased number of medicines used were: female gender ( $p=0.019)$, a lower level of education ( $p=0.003)$, a high number of hospital admissions $(p=0.000)$, clinics visited by the patient $(p=0.000)$, and number of comorbidities $(p=0.000)$. The most commonly used medications ( $82.6 \%$ of the study population) were blood glucose-lowering agents, excluding insulin. Other commonly used medications were antihypertensive drugs and lipid-modifying agents. Conclusion: A significant sector of the older Kuwaiti patient population has a high prevalence of polypharmacy and is thus exposed to its potential hazards. The current study highlights the need to revise the drug-dispensing policy among community-dwelling, older Kuwaiti people, as well as to initiate educational programs among healthcare practitioners concerning prescribing issues in older individuals.

(c) 2019 The Author(s)

Published by S. Karger AG, Basel

\begin{tabular}{ll}
\hline KARGER & $\begin{array}{l}\text { @ } 2019 \text { The Author(s) } \\
\text { Published by S. Karger AG, Basel }\end{array}$ \\
karger@karger.com & $\begin{array}{l}\text { Karger } \\
\text { This is an Open Access article licensed under the Creative Commons }\end{array}$ \\
www.karger.com/mpp & $\begin{array}{l}\text { Attribution-NonCommercial-4.0 International License (CC BY-NC) } \\
\text { (http://www.karger.com/Services/OpenAccessLicense), applicable to } \\
\text { the online version of the article only. Usage and distribution for com- } \\
\text { mercial purposes requires written permission. }\end{array}$
\end{tabular}

Nabil Ahmed Badawy

Department of Biomedical Science, College of Nursing Public Authority for Applied Education and Training PO Box 23167, Safat, Al Shuwaikh 13092 (Kuwait)

E-Mail na.badawy@paaet.edu.kw 


\section{Introduction}

The United Nations Department of Economic and Social Affairs reported that the population older than 60 years is expected to grow by $56 \%$ globally between 2015 and 2030, and those over the age of 65 years will account for more than half of the world's population by the year 2030 [1].

The use of drugs in older adults has been the subject of much consideration in recent years. Several studies have shown an increasing prevalence of multiple drug use in the frail, older population. In a study by Carmona-Torres et al. [2], they concluded that the prevalence rates of polypharmacy (PP) and self-medication in Spain were considerable, and these rates increased significantly from 2006 to 2014. Older people often suffer from multiple chronic diseases that can accumulate with age, and physicians must follow evidence-based guidelines for chronic disease management [3]. Multiple drug use refers to $P P$, which is a particular public health concern in older people [4]. Agreement on the definition of PP is still lacking. The World Health Organization (WHO) defines PP as "the administration of many drugs at the same time or the administration of an excessive number of drugs" [5]. A simple definition of PP is "taking 5 or more medicines concomitantly" [6]. Another definition of PP is the "consumption of more medicines than clinically indicated or by the consumption of medicines that are not clinically indicated" [7]. The use of multiple drug treatments can be clinically appropriate for individuals with different diseases if it improves their health and quality of life. However, PP is also a well-known risk factor in older people because their vulnerability to pharmaceutical products is increased and due to drug-drug interactions, adverse drug reactions, and a low adherence to drug therapy.

PP poses unique challenges for clinicians because it exposes many older adults to risks beyond the point where drug therapy is useful [8]. Additionally, it is assumed to cause needless health expenditures, directly due to redundant drug sales and indirectly due to the increased level of hospitalization caused by a drug-related adverse effect [7]. Accordingly, there have been many efforts to reduce the number of prescribed drugs to individuals with $\mathrm{PP}$, especially for older people [9].

Physicians, pharmacists, and patients are all responsible. Suboptimal and inappropriate prescribing usually ends in PP. Suboptimal prescribing associated with PP includes the prescription of $>1$ medicine with the same effect or prescribing medications that interact with each other. A prescribing cascade occurs when physicians pre- scribe additional drugs to treat the side effects of other drugs [10]. Patients are also responsible for the problem by self-medicating, failing to follow the instructions of physicians, or not reporting all over-the-counter (OTC) medications used.

Kuwaiti researchers have still not identified the magnitude of PP or its associated risk factors in older Kuwaiti patients. To optimize the use of medications, we must identify an equilibrium between the adequate treatment of diseases and avoiding the side effects of drugs. It is imperative to identify both modifiable factors influencing the occurrence of PP and inappropriate practices. Accordingly, we can develop programs to modify these factors and promote safer care for older patients.

Our hypothesis was that the problem of PP and its worrisome consequences may exist in many older $\mathrm{Ku}$ waiti patients.

This study aimed to estimate the prevalence of PP in community-dwelling, older Kuwaiti patients, describe the number and types of drugs used, and identify risk factors associated with PP.

\section{Subjects and Methods}

\section{Study Design}

A descriptive cross-sectional questionnaire-based survey was used.

\section{Inclusion Criteria}

Community-dwelling, older Kuwaiti patients over 65 years of age who could communicate coherently and relevantly and agreed to participate in the study were included.

\section{Study Sample}

We used the nonprobability convenient sampling method. Potential participants were recruited from geriatric clinics and chronic disease follow-up clinics at primary health centers in the $6 \mathrm{Ku}$ waiti governorates. The sample size was 500 elderly patients, and the number of recruited cases from each governorate was according to the ratio of its population to the total Kuwaiti population.

\section{Data Collection}

The data were collected over a 4-month period from March to July 2017 using a questionnaire employed previously in similar studies. A trained nurse administered the questionnaire during an interview with the patient at their respective health care center. Ethical clearance was obtained from the Standing Committee Coordinating Medical and Health Research, Ministry of Health of Kuwait. All of the participants answered the questionnaire after signing informed consent documents to participate in this study.

\section{Survey Development}

The questionnaire included 3 sections. The first section included the following demographic data: age, sex, level of education, 
marital status, residency, monthly income, and BMI. The second section included questions about current health problems, a list of the medications in use, and whether these were prescription or OTC medications. We classified medications according to the WHO Anatomical Therapeutic Chemical classification system [11]. The third section encompassed questions revealing the pattern of drug use and awareness of proper use, as well as identification of any side effects related to the utilization of these medications. Overcoming information bias occurred by avoiding leading questions in the questionnaire and offering categorized values for subjects to select instead of requesting specific values.

\section{Data Analysis}

The collected questionnaires were checked for completeness before data entry. SPSS for Windows (release 22; SPSS Inc., Chicago, IL, USA) was used for statistical analysis. Analysis of the demographic variables was performed using Pearson's $\chi^{2}$ test for categorical data. The calculation of $p$ values was achieved using ANOVA for continuous variables and a $\chi^{2}$ test for categorical variables. For all significant differences, we calculates the OR and CI. $p<0.05$ was considered statistically significant. We performed multivariate ordinal logistic regression to estimate OR and their 95\% CI to investigate the possible risk factors for PP.

\section{Study Definitions}

The nonpolypharmacy (NP) subgroup included patients using 4 or fewer drugs concomitantly. The use of 5-8 drugs during the last 3-month period was the cut-off indicating the existence of PP, while the use of $>8$ drugs indicated excessive polypharmacy (EPP) [7]. The counted medications included prescribed and OTC medications, including dietary supplements such as herbs, minerals, and vitamins. We counted combined formulations as separate medications.

\section{Results}

Five hundred patients were enrolled into this study. Table 1 indicates the number of persons who were approached from each governorate. Ninety-six percent of the patients agreed to participate, and data were missing in $<3 \%$ of the cases.

The age of the patients ranged from 65 to 87 years, with a mean age of $71.73 \pm 5.32$ years. Fifty percent $(n=250)$ of the studied patients were between 65 and 70 years of age, $22 \%(n=110)$ were aged between 71 and 75 years, $22.8 \%$ $(n=114)$ were aged between 76 and 80 years, and only $5.2 \%$ $(n=26)$ were aged over 80 years. Males made up 52\% $(n=$ 260 ) of the sample. Fifty-six percent of the patients had an education level below secondary school, and $44 \%$ had finished secondary school or higher. Table 1 provides information about the demographic data of the patients.

Our study showed a PP prevalence of $58.4 \%(n=292)$, while those of NP and EPP were $31.4 \%(n=157)$ and $10.2 \%(n=51)$, respectively.
Table 1. Demographic data of the patients

\begin{tabular}{|c|c|c|}
\hline Variable & $n$ & $\%$ \\
\hline \multicolumn{3}{|l|}{ Governorate } \\
\hline Ahmadi & 105 & 21.0 \\
\hline Farwaniya & 99 & 19.8 \\
\hline Hawalli & 88 & 17.7 \\
\hline Jahra & 71 & 14.0 \\
\hline Moubark Al Kabeer & 71 & 14.0 \\
\hline Capital & 67 & 13.5 \\
\hline \multicolumn{3}{|l|}{ Age (years) } \\
\hline $65-70$ & 250 & 50.0 \\
\hline $71-75$ & 110 & 22.0 \\
\hline $76-80$ & 114 & 22.8 \\
\hline$>80$ & 26 & 5.2 \\
\hline \multicolumn{3}{|l|}{ Sex } \\
\hline Female & 240 & 48.0 \\
\hline Male & 260 & 52.0 \\
\hline \multicolumn{3}{|l|}{ Level of education } \\
\hline Lower than secondary school & 278 & 55.6 \\
\hline Higher than secondary school & 222 & 44.4 \\
\hline \multicolumn{3}{|l|}{ Social status } \\
\hline Married & 371 & 74.2 \\
\hline Widow & 109 & 21.8 \\
\hline Single & 14 & 2.8 \\
\hline Divorced & 6 & 1.2 \\
\hline \multicolumn{3}{|l|}{ Residency } \\
\hline With the family & 480 & 96.0 \\
\hline Alone & 20 & 4.0 \\
\hline \multicolumn{3}{|l|}{ Monthly income (KD) } \\
\hline $1,000-2,000$ & 217 & 43.4 \\
\hline $600-1,000$ & 186 & 37.2 \\
\hline$<600$ & 50 & 10.0 \\
\hline$>2,000$ & 47 & 9.4 \\
\hline \multicolumn{3}{|l|}{ BMI } \\
\hline $18.5-24.9$ & 344 & 68.8 \\
\hline 25-29.9 & 119 & 23.8 \\
\hline$<18.5$ & 23 & 4.6 \\
\hline Over 30 & 13 & 2.6 \\
\hline $25-29.5$ & 1 & 0.2 \\
\hline
\end{tabular}

The drugs most commonly used by our patients were blood glucose-lowering agents; $82.6 \%(n=413)$ of the patients used blood glucose-lowering agents excluding insulin, and $37.2 \%(n=186)$ used insulin and analogs. Other commonly used medications were antihypertensive drugs and lipid-modifying agents. Table 2 shows a detailed description of the various medications used by the studied cases.

The $\chi^{2}$ test of independence showed a statistically significant relationship between PP and several potential risk factors. Table 3 indicates that the percentage of females in the EPP subgroup was significantly higher than that of males in the EPP subgroup (14.2 vs. 6.5\%, respec- 
Table 2. Medications used by the patients

\begin{tabular}{lrr}
\hline Medications & $n$ & $\%$ \\
\hline Blood glucose-lowering agents excluding insulin & 413 & 82.6 \\
Insulin and analogs & 186 & 37.2 \\
Antihypertensive medications & & \\
$\quad$ Calcium channel blockers & 217 & 43.4 \\
Agents acting on the angiotensin system & & \\
$\quad$ Angiotensin II antagonists & 100 & 20 \\
$\quad$ Plain ACE inhibitors used by & 97 & 19.4 \\
$\quad$ Agents acting on the angiotensin system and & 63 & 12.6 \\
$\quad$ Selective $\beta$-blocking agents & 96 & 19 \\
Lipid-modifying agents, statins & 333 & 66.6 \\
Acetylsalicylic acid preparations & 303 & 60.6 \\
Supplements & 297 & 59.4 \\
Proton pump inhibitors & 126 & 25 \\
Bronchodilators & 89 & 18 \\
Thyroid hormones & 70 & 14 \\
Benzodiazepines & 18 & 3.6 \\
Antidepressants & 12 & 2.4 \\
\hline
\end{tabular}

tively; $\left.\chi^{2}[2]=7.97 ; p=0.019\right)$. Patients with less than a secondary school education showed a higher percentage of EP with a statistically significant difference than those with a level of education higher than secondary school ( 14.7 vs. $4.5 \%$, respectively; $\chi^{2}[10]=26.92 ; p=0.003$ ). According to the number of hospital admissions in the last 2 years, we divided the patients into 3 subgroups. The first subgroup had no history of hospital admissions, the second subgroup had 1-2 admissions, and the third had $>2$ admissions. This study showed a statistically significant incremental increase in the percentage of PP from the first to the third subgroup, i.e., $39,66.8$, and $80 \%$, respectively. Additionally, the percentage of EPP increased from $6.4 \%$ in the first group to 11.6 and $17.5 \%$ in the second and third groups, respectively $\left(\chi^{2}[8]=81.76\right.$; $p<$ 0.001 ). A significant relationship existed between the number of drugs taken by the patient and a positive history of falls and unbalance. Thus, in patients with NP, only $15.3 \%$ reported a history of falls or unbalance compared with 45.5 and $60.8 \%$ in patients with PP and EPP, respectively $\left(\chi^{2}[2]=52.86 ; p<0.001\right)$. Considering the relationship between the number of clinics attended by the patient and PP, patients who visited only 1 clinic had a higher percentage of NP than those who visited 2 or $>2$ clinics (62.4 vs. 22.5 vs. $3.8 \%$, respectively; $p<0.001$ ). In contrast, patients who visited $>2$ clinics had a higher percentage of EPP than those who visited 2 or 1 clinic $(38.5$ vs. 9.8 vs. $5.6 \%$, respectively; $p<0.001)$. The results showed a statistically significant incremental increase in

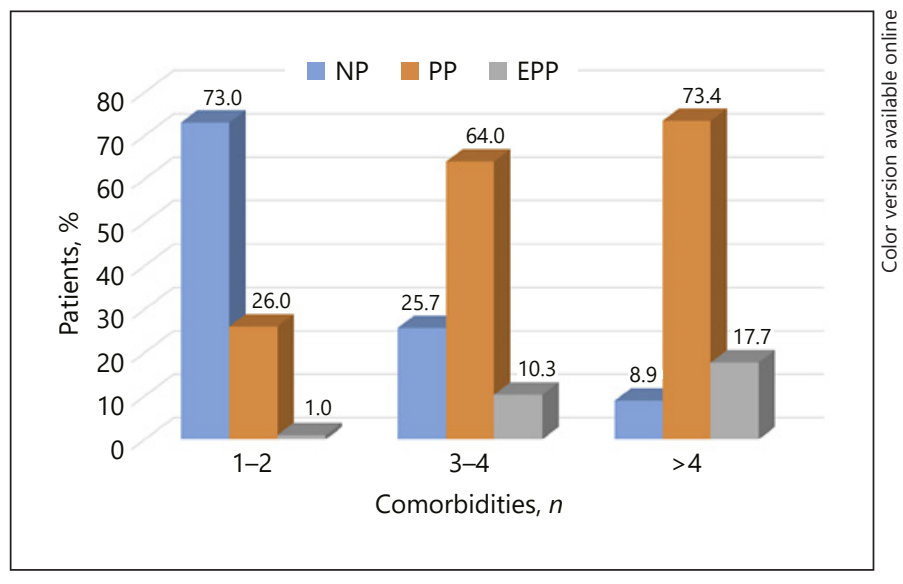

Fig. 1. Relation between the prevalence of NP, PP, and EPP and the number of comorbidities.

the percentage of PP and EPP as the number of comorbidities increased ( $p<0.001$; Fig. 1$)$.

A multinomial logistic regression analysis was conducted for each independent variable and OR were computed to shows the extent that each independent variable affects the probability that a case is a member of 1 group versus a reference group.

The results of the multinomial logistic regression model were significant, i.e., $\chi^{2}(18)=227.38(p<0.001)$, suggesting that sex, level of education, number of hospital admissions, falls and unbalance, and number of comorbidities all had a significant effect on the odds of observing at least 1 response category considering PP or EPP relative to NPP.

Table 4 indicates the results of examining the effects of these variables. The regression coefficient for female sex considering PP was not significant, while it was significant for EPP $\left(B=2.60, \chi^{2}=5.57, p=0.009\right.$, OR 6.82), indicating that being female had a significant effect on the odds of observing EPP relative to NPP. The regression coefficients for level of education lower than secondary school, number of hospital admissions $>2$, history of falls and unbalance, and number of comorbidities $>4$ was significant, indicating that these variables have a significant effect on the odds of observing PP and EPP relative to NPP.

\section{Discussion}

Despite increasing awareness of adverse reactions related to multidrug exposure, the prevalence of PP remains high in older adults. The most worrying concern 
Table 3. Relationship between $\mathrm{PP}$ and potential risk factors (significant relations)

\begin{tabular}{|c|c|c|c|c|c|c|}
\hline \multirow[t]{2}{*}{ Studied factor } & \multicolumn{6}{|l|}{ Drugs, $n$} \\
\hline & $0-4$ & $5-8$ & $>8$ & $x^{2}$ & d.f. & $p$ value \\
\hline \multicolumn{7}{|l|}{ Sex } \\
\hline Female $(n=240)$ & $71(29.6)$ & $135(56.3)$ & $34(14.2)$ & 7.97 & 2 & 0.019 \\
\hline Male $(n=260)$ & $86(33.1)$ & $157(60.4)$ & $17(6.5)$ & & & \\
\hline \multicolumn{7}{|l|}{ Level of education } \\
\hline Lower than secondary school & $76(27.3)$ & $161(57.9)$ & $41(14.7)$ & 26.92 & 10 & 0.003 \\
\hline Higher than secondary school & $81(36.5)$ & $131(59.0)$ & $10(4.5)$ & & & \\
\hline \multicolumn{7}{|l|}{ Hospital admissions $(n)$} \\
\hline None $(n=174)$ & $95(54.6)$ & $68(39.0)$ & $11(6.4)$ & & & \\
\hline $1-2(n=286)$ & $61(21.3)$ & $191(66.8)$ & $34(11.6)$ & & & \\
\hline$>2(n=40)$ & $1(2.5)$ & $32(80.0)$ & $7(17.5)$ & 81.76 & 8 & $<0.001$ \\
\hline \multicolumn{7}{|l|}{ History of falls } \\
\hline No $(n=312)$ & $133(84.7)$ & $159(54.5)$ & $20(39.2)$ & & & \\
\hline Yes $(n=188)$ & $24(15.3)$ & $133(45.5)$ & $31(60.8)$ & 52.86 & 2 & $<0.001$ \\
\hline \multicolumn{7}{|l|}{ Visited clinics $(n)$} \\
\hline $1(n=125)$ & $78(62.4)$ & $40(32.0)$ & $7(5.6)$ & & & \\
\hline $1(n=346)$ & $78(22.5)$ & $234(67.6)$ & $34(9.8)$ & & & \\
\hline$>2(n=26)$ & $1(3.8)$ & $15(57.7)$ & $10(38.5)$ & 95.77 & 4 & $<0.001$ \\
\hline \multicolumn{7}{|l|}{ Comorbidities $(n)$} \\
\hline $1-2(n=104)$ & $76(73.0)$ & $27(26.0)$ & $1(1.0)$ & 120.93 & 4 & $<0.001$ \\
\hline $3-4(n=272)$ & $70(25.7)$ & $174(64.0)$ & $28(10.3)$ & & & \\
\hline$>4(n=124)$ & $11(8.9)$ & $91(73.4)$ & $22(17.7)$ & & & \\
\hline
\end{tabular}

Values are presented as numbers (\%) unless otherwise stated.

of PP is not only the occurrence of adverse drug reactions but also the effects on the patients' quality of life and increased drug costs [12]. Currently, no data are available concerning the prevalence of PP in community-dwelling, older Kuwaiti patients. This study aimed to assess the prevalence, commonly used drugs, and risk factors associated with PP among older adults taking chronic medications in the community setting in $\mathrm{Ku}$ wait.

All of the studied patients were aged older than 65 years. The prevalence rates of PP and EPP were 58.4\% $(n=292)$ and $10.2 \%(n=51)$, respectively. Previous studies have shown a similarly high prevalence of PP in other countries such as Sweden and China [13,14]. A study of the Korean elderly population showed a higher PP prevalence of $86.4 \%$ [15].

Several previous studies have shown the association between endocrine or cardiovascular disease and a significant increase in medication use compared to other disease conditions [16]. In the current study, blood glucose-lowering agents were the most commonly used drugs: $82.6 \%(n=413)$ of the patients used blood glu- cose-lowering agents excluding insulin, and $37.2 \%$ ( $n=$ 186) of the patients used insulin and/or its analogs. Other commonly used medications were antihypertensive drugs and lipid-modifying agents. In Kuwait, the prevalence of type 2 diabetes is $25.4 \%$, which increases to $56.3 \%$ in the age group $>55$ years, and that of hypertension is $28 \%$. The prevalence of the cooccurrence of diabetes and hypertension is $17 \%$ among older adults [17]. Previous reports have found that older patients with hypertension and diabetes might be overly treated to reach predetermined treatment targets. This aggressive treatment may expose patients to attacks of hypoglycemia and hypotension, which, in turn, may lead to falls, head injuries, or fractures. These events are likely to have a negative impact on the patient's physical function and quality of life [18]. Therefore, many treatment strategies recommend a less intense approach in managing elderly patients with diabetes mellitus or hypertension, although this may not widely be practiced [19]. Although prescribing multiple drugs to patients with comorbid conditions can improve their health status and clinical condition, PP also can increase the risk of ad- 
Table 4. Multinomial logistic regression with the number of medicines taken predicted by sex, level of education, hospital admissions, falls and unbalance, number of comorbidities, and number of clinics visited by the patient

\begin{tabular}{|c|c|c|c|c|c|c|}
\hline Variable & Response, $n$ & $B$ & SE & $\chi^{2}$ & $p$ value & OR \\
\hline Intercept & $5-8$ & 2.33 & 0.34 & 46.22 & $<0.001$ & \\
\hline \multicolumn{7}{|l|}{ Sex } \\
\hline Male & $5-8$ & -0.20 & 0.26 & 0.57 & 0.449 & 0.82 \\
\hline Female & $5-8$ & -0.65 & 0.39 & 0.51 & 0.549 & 0.62 \\
\hline \multicolumn{7}{|l|}{ Level of education } \\
\hline Higher than secondary school & $5-8$ & -0.15 & 0.27 & 0.32 & 0.572 & 0.86 \\
\hline Lower than secondary school & $5-8$ & 2.15 & 1.27 & 4.32 & $<0.001$ & 6.86 \\
\hline \multicolumn{7}{|l|}{ Hospital visits $(n)$} \\
\hline None & $5-8$ & -0.99 & 0.26 & 14.74 & $<0.001$ & 0.37 \\
\hline$>2$ & $5-8$ & 2.44 & 1.09 & 5.01 & 0.025 & 11.49 \\
\hline Falls and unbalance & $5-8$ & 1.28 & 0.29 & 9.17 & 0.002 & 3.42 \\
\hline \multicolumn{7}{|l|}{ Comorbidities $(n)$} \\
\hline$>4$ & $5-8$ & 0.75 & 0.37 & 4.10 & 0.043 & 2.13 \\
\hline $1-2$ & $5-8$ & -1.59 & 0.30 & 28.39 & $<0.001$ & 0.20 \\
\hline \multicolumn{7}{|l|}{ Clinics visited by the patient $(n)$} \\
\hline 1 & $5-8$ & -1.08 & 0.28 & 15.15 & $<0.001$ & 0.34 \\
\hline 3 & $5-8$ & 0.75 & 1.07 & 0.49 & 0.483 & 2.12 \\
\hline Intercept & $>8$ & 0.99 & 0.44 & 5.08 & 0.024 & \\
\hline \multicolumn{7}{|l|}{ Sex } \\
\hline Male & $>8$ & -0.78 & 0.42 & 3.47 & 0.063 & 0.46 \\
\hline Female & $>8$ & 2.60 & 1.76 & 5.57 & 0.009 & 6.82 \\
\hline \multicolumn{7}{|l|}{ Level of education } \\
\hline Higher than secondary school & $>8$ & -1.09 & 0.46 & 5.69 & 0.017 & 0.34 \\
\hline Lower than secondary school & $>8$ & 1.15 & 1.27 & 6.32 & $<0.001$ & 7.90 \\
\hline \multicolumn{7}{|l|}{ Hospitals $(n)$} \\
\hline None & $>8$ & -0.68 & 0.45 & 2.34 & 0.126 & 0.51 \\
\hline$>2$ & $>8$ & 2.59 & 1.18 & 4.78 & 0.029 & 13.30 \\
\hline Falls and unbalance & $>8$ & 1.26 & 0.41 & 9.33 & 0.002 & 2.28 \\
\hline \multicolumn{7}{|l|}{ Comorbidities $(n)$} \\
\hline$>4$ & $>8$ & 1.07 & 0.47 & 5.23 & 0.022 & 2.92 \\
\hline $1-2$ & $>8$ & -3.00 & 1.05 & 8.14 & 0.004 & 0.05 \\
\hline \multicolumn{7}{|l|}{ Clinics visited by the patient $(n)$} \\
\hline 1 & $>8$ & -0.82 & 0.50 & 2.62 & 0.105 & 0.44 \\
\hline 3 & $>8$ & 1.96 & 1.12 & 3.05 & 0.081 & 7.09 \\
\hline
\end{tabular}

verse drug interactions, e.g., hyponatremia or postural hypotension with diuretics or antihypertensive agents. These side effects can sometimes be sufficiently severe to necessitate hospital admission and occasionally even result in death.

Linking PP to gender is variable in the literature. In a study by Jyrkkä et al. [20], polypharmacy was higher in males than in females. Conversely, many other studies have reported a correlation between PP and female gender [18]. In the current study, $14.2 \%$ of females had EPP compared to $6.5 \%$ of males, and this difference was statistically significant $(p=0.019)$. Payne et al. [12] conducted a Scottish study that showed a similar finding. Such dif- ferences in the literature could be due to dissimilarities in physicians' prescription attitude toward males and females who may also have differences in educational and socioeconomic characteristics. The association between gender and PP may need more elaboration in future research.

Our results suggested a significant relationship between PP and some other potential risk factors. The level of education was a significant risk factor for PP. The results showed that patients with less than a secondary school education had a high percentage of EPP with a statistically significant difference compared to those with a level of education higher than secondary school (14.7 vs. 
$4.5 \%$, respectively; $p=0.003)$. Charlesworth et al. [21] documented the same findings; subjects with a low education in their study had a higher probability of PP and EPP. A cross-European study by Gallagher et al. [22] reported hospital admission as an important driving factor behind PP. In the current study, the effect of hospital admissions on the number of drugs taken was evident. The results showed a statistically significant incremental increase in the percentage of $\mathrm{PP}$ and EPP in relations to the number of hospital admissions $\left(\chi^{2}(8)=81.76 ; p<0.001\right)$. The study of Kim et al. [15] showed that PP was more frequent with an increasing number of visits to different healthcare organizations. Our results showed a statistically significant correlation between the number of drugs taken and the number of clinics visited by the patient $(p<0.001)$. Previous reports indicated that overlapping medications with the switching of healthcare providers is a severe problem [23]. Multiclinic visits encourage overprescription, which invariably leads to PP because more than 1 doctor is responsible for the treatment of the same patient. Kuwaiti patients have a fully covered health insurance system with free health services. In many instances, the patient visits clinics for only minor complaints. Another issue in Kuwait is that most physicians in the outpatient clinics are non-Kuwaiti, making it difficult for them to refuse the demands of Kuwaiti patients. Richardson et al. [24] showed in a univariate analysis that the incidence of PP in individuals paying for health insurance or health services is less than that in those receiving free or subsidized healthcare services. A literature review showed that an increasing number of comorbidities is one of the predictors of $\mathrm{PP}$ in the older patient population [26].

Our results showed a statistically significant incremental increase in the percentage of PP and EPP as the number of comorbidities increases. Patients with comorbid medical conditions always require several drugs to treat each condition. It is rational for those patients to be on 6-8 medications to reduce their long-term risk for those conditions [21]. The increase in the prevalence of $\mathrm{PP}$ with comorbidities may be due to several reasons, including changes in evidence-based recommendations. Additionally, the introduction of new specific drugs for the management of certain conditions or diseases may play a role. Finally, physicians are now prescribing more drugs for preventive use. Altogether, these factors may have resulted in a change in the prescription patterns. There is a strong association between PP in older individuals and multiple negative health outcomes, including increased costs of health care [25], functional disabilities, falls [26], and harmful drug-drug interactions [27]. Our results showed a significant correlation between the number of drugs taken by the patient and a positive history of falls and unbalance. In patients with NPP, only $15.3 \%$ reported a history of falls or unbalance. This result is in comparison to 45.5 and $60.8 \%$ in patients with $\mathrm{PP}$ and EPP, respectively $(p<0.001)$. In lieu of pharmacologic measures, nurses should use patient-centered, evidencebased nonpharmacologic strategies to treat common symptoms [28].

One limitation of this study was that we related the incidence of falls not to the use of specific medications but rather to the total number of drugs used. Other limitations may be related to inaccuracy in recording dietary supplements, thus resulting in the underestimation of the true prevalence of PP. We used the nonprobability convenient sampling method, which may negatively impact the applicability of the results to the general population. Additionally, it was not possible to establish causal relationships due to the cross-sectional study design.

\section{Conclusion}

A significant sector of the older Kuwaiti patient population has a high prevalence of polypharmacy and thus are exposed to its potential hazards. The findings of the current study highlight the need to revise the drug-dispensing policy among the community-dwelling, older $\mathrm{Ku}$ waiti population and to initiate educational programs among healthcare practitioners concerning prescribing issues in regard to older individuals. Individuals diagnosed with diabetes mellitus and cardiovascular diseases are more susceptible to polypharmacy; thus, physicians and pharmacists should be cautious to prevent any adverse effects of drug-drug interactions. There is a need to establish innovative clinical strategies in which the health professionals and patients are involved to improve the personal reliability with medicines and reduce the risks and costs of polypharmacy and self-medication. Nurses should refer to Beers criteria and Screening Tool of Older Person's potentially inappropriate Prescriptions (STOPP) criteria when questioning the appropriateness of an elderly patient's medications.

In the future, it is suggested that the Ministry of Health in Kuwait should investigate an approach for medication management, such as a clinical decision support system to guide evidence-based prescribing and the involvement of clinical pharmacists in collaborative care. 


\section{Acknowledgment}

We thank Dr. Ahmed Al Saber for the design and development of the study database.

\section{Funding Sources}

We acknowledge the Public Authority for Applied Education and Training, Kuwait, for funding and making this research project possible (funded grant number No. CN-16-02).

\section{References}

1 United Nations Department of Economic and Social Affairs: World population aging 2015; 2015. Report No.: ST/ESA/SER.A/390.

2 Carmona-Torres JM, Cobo-Cuenca AI, Recio-Andrade B, Laredo-Aguilera JA, Martins MM, Rodríguez-Borrego MA. Prevalence and factors associated with polypharmacy in the older people: 2006-2014. J Clin Nurs. 2018 Aug;27(15-16):2942-52.

3 Molokhia M, Majeed A. Current and future perspectives on the management of polypharmacy. BMC Fam Pract. 2017 Jun;18(1):70.

4 Lapi F, Pozzi C, Mazzaglia G, Ungar A, Fumagalli S, Marchionni N, et al. Epidemiology of suboptimal prescribing in older, community dwellers: a two-wave, population-based survey in Dicomano, Italy. Drugs Aging. 2009; 26(12):1029-38.

5 WHO Centre for Health Development. Aging and health technical report. A glossary of terms for community health care and services for older persons. World Health Organization, editor. $2004 \mathrm{WHO} / \mathrm{WKC} / \mathrm{Tech} . S e r . / 04$. 2. Geneva, Switzerland.

6 Hovstadius B, Petersson G. Factors leading to excessive polypharmacy. Clin Geriatr Med. 2012 May;28(2):159-72.

7 Maher RL, Hanlon J, Hajjar ER. Clinical consequences of polypharmacy in elderly. Expert Opin Drug Saf. 2014 Jan;13(1):57-65.

8 Wauters M, Elseviers M, Vaes B, Degryse J, Dalleur O, Vander Stichele R, et al. Too many, too few, or too unsafe? Impact of inappropriate prescribing on mortality, and hospitalization in a cohort of community-dwelling oldest old. Br J Clin Pharmacol. 2016 Nov;82(5): 1382-92.

9 Jansen J, Naganathan V, Carter SM, McLachlan AJ, Nickel B, Irwig L, et al. Too much medicine in older people? Deprescribing through shared decision making. BMJ. 2016 Jun; 353:i2893.

10 Ahmad A, Hugtenburg J, Welschen LM, Dekker JM, Nijpels G. Effect of medication review and cognitive behaviour treatment by community pharmacists of patients discharged from the hospital on drug related problems and compliance: design of a randomized controlled trial. BMC Public Health. 2010 Mar;10(1):133.
11 WHO Collaborating Centre for Drug Statistics Methodology. Guidelines for ATC classification and DDD assignment 2015. Oslo: Norwegian Institute of Public Health; 2014.

12 Payne RA, Avery AJ, Duerden M, Saunders CL, Simpson CR, Abel GA. Prevalence of polypharmacy in a Scottish primary care population. Eur J Clin Pharmacol. 2014 May; 70(5):575-81.

13 Hovstadius B, Hovstadius K, Astrand B, Petersson $\mathrm{G}$. Increasing polypharmacy - an individual-based study of the Swedish population 2005-2008. BMC Clin Pharmacol. 2010 Dec;10(1):16.

14 Dong L, Yan H, Wang D. Polypharmacy and its correlates in village health clinics across 10 provinces of Western China. J Epidemiol Community Health. 2010 Jun;64(6):549-53.

15 Kim HA, Shin JY, Kim MH, Park BJ. Prevalence and predictors of polypharmacy among Korean elderly. PLoS One. 2014 Jun; 9(6):e98043.

16 Walckiers D, Van der Heyden J, Tafforeau J: Factors associated with excessive polypharmacy in older people. Arch Public Health. 2015 Nov; $73: 50$.

17 Sims OT, Oh H, Noh H, Melton PA, Sheffield $\mathrm{S}$, Ingram $\mathrm{K}$, et al. Prevalence and predictors of co-occurring diabetes and hypertension in community-dwelling older adults. Geriatr Gerontol Int. 2018 Sep;18(9):1356-60.

18 Tinetti ME, Han L, Lee DS, McAvay GJ, Peduzzi P, Gross $\mathrm{CP}$, et al. Antihypertensive medications and serious fall injuries in a nationally representative sample of older adults. JAMA Intern Med. 2014 Apr;174(4):588-95.

19 Lipska KJ, Ross JS, Miao Y, Shah ND, Lee SJ, Steinman MA. Potential overtreatment of diabetes mellitus in older adults with tight glycemic control. JAMA Intern Med. 2015 Mar; 175(3):356-62.
20 Jyrkkä J, Enlund H, Korhonen MJ, Sulkava R, Hartikainen S. Polypharmacy status as an indicator of mortality in an elderly population. Drugs Aging. 2009;26(12):1039-48.

21 Charlesworth CJ, Smit E, Lee DS, Alramadhan F, Odden MC. Polypharmacy among adults aged 65 years and older in the United States: 1988-2010. J Gerontol A Biol Sci Med Sci. 2015 Aug;70(8):989-95.

22 Gallagher P, Lang PO, Cherubini A, Topinková E, Cruz-Jentoft A, Montero Errasquín $B$, et al. Prevalence of potentially inappropriate prescribing in an acutely ill population of older patients admitted to six European hospitals. Eur J Clin Pharmacol. 2011 Nov;67(11):1175-88.

23 Shin JY, Choi NK, Jung SY, Kim YJ, Seong JM, Park BJ. Overlapping medication associated with healthcare switching among Korean elderly diabetic patients. J Korean Med Sci. 2011 Nov;26(11):1461-8.

24 Richardson K, Kenny RA, Bennett K. The effect of free health care on polypharmacy: a comparison of propensity score methods and multivariable regression to account for confounding. Pharmacoepidemiol Drug Saf. 2014 Jun;23(6):656-65.

25 Hovstadius B, Petersson G: The impact of increasing polypharmacy on prescribed drug expenditure-a register-based study in Sweden 2005-2009. Health Policy. 2013 Feb;109:16674.

26 Fried TR, O'Leary J, Towle V, Goldstein MK, Trentalange M, Martin DK. Health outcomes associated with polypharmacy in community-dwelling older adults: a systematic review. J Am Geriatr Soc. 2014 Dec;62(12):2261-72.

27 Loya AM, González-Stuart A, Rivera JO. Prevalence of polypharmacy, polyherbacy, nutritional supplement use and potential product interactions among older adults living on the United States-Mexico border: a descriptive, questionnaire-based study. Drugs Aging. 2009;26(5):423-36.

28 Kim J, Parish AL. Polypharmacy and medication management in Older Adults. Nurs Clin North Am. 2017 Sep;52(3):457-68. 